\title{
Erratum to: Housing price prediction: parametric versus semi-parametric spatial hedonic models
}

\author{
José-María Montero' ${ }^{1}$ Román Mínguez ${ }^{2}$ • \\ Gema Fernández-Avilés ${ }^{1}$
}

\section{Erratum to: J Geogr Syst DOI 10.1007/s10109-017-0257-y}

In the original publication, in Table 1, there is a misprint in equations under models SDEM and SEM. The specification for the spatially correlated error term, $\mathbf{u}$, must be $\mathbf{u}=\lambda \mathbf{W u}+\boldsymbol{\varepsilon}$. The correct versions of these equations are given below. The original version of the article has been updated (Table 1).

The online version of the original article can be found under doi:10.1007/s10109-017-0257-y.

José-María Montero

jose.mlorenzo@uclm.es

1 Department of Statistics, Faculty of Law and Social Sciences, University of Castilla-La Mancha, 45071 Toledo, Spain

2 Department of Statistics, Faculty of Social Sciences, University of Castilla-La Mancha, 16071 Cuenca, Spain 


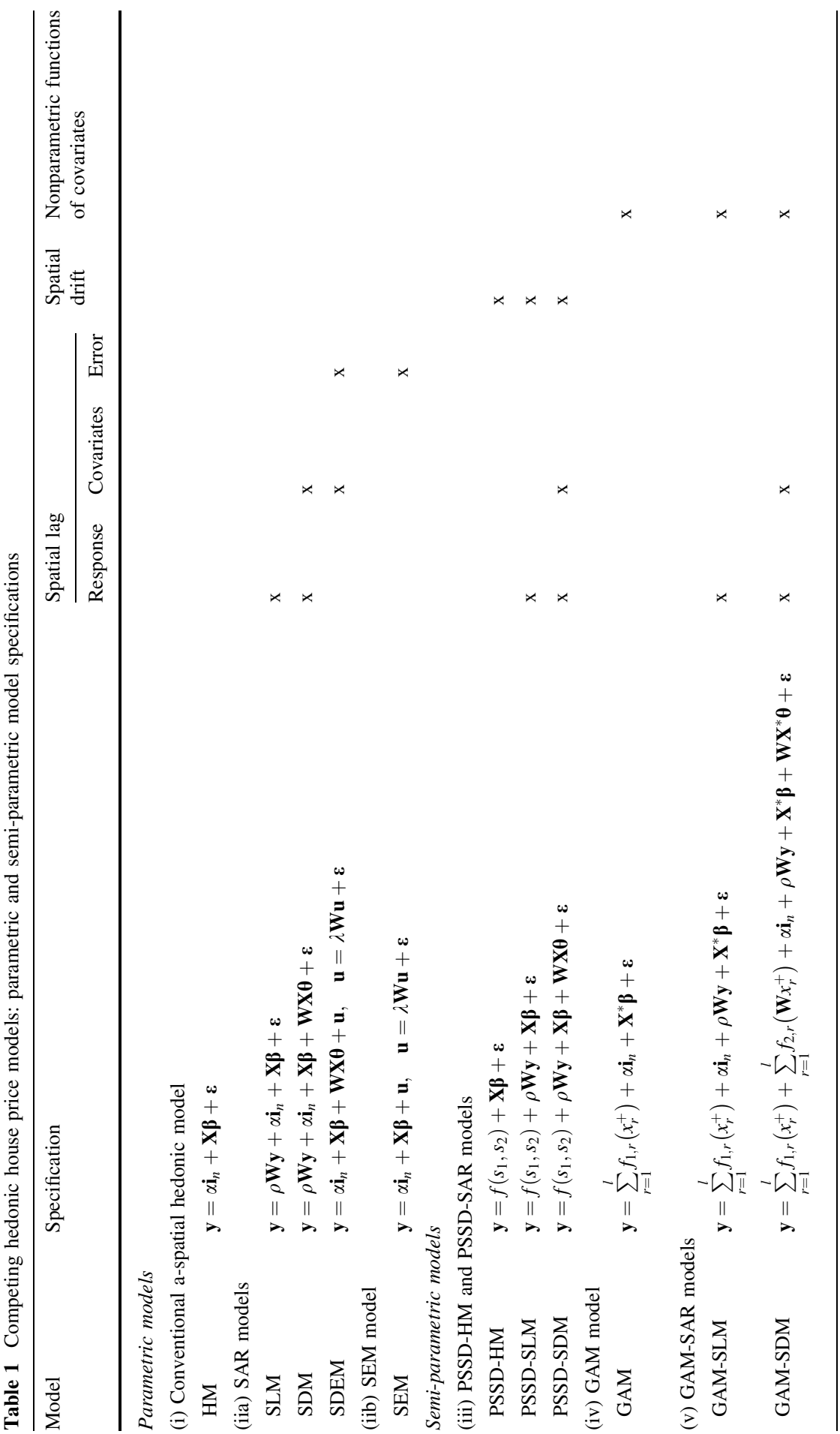




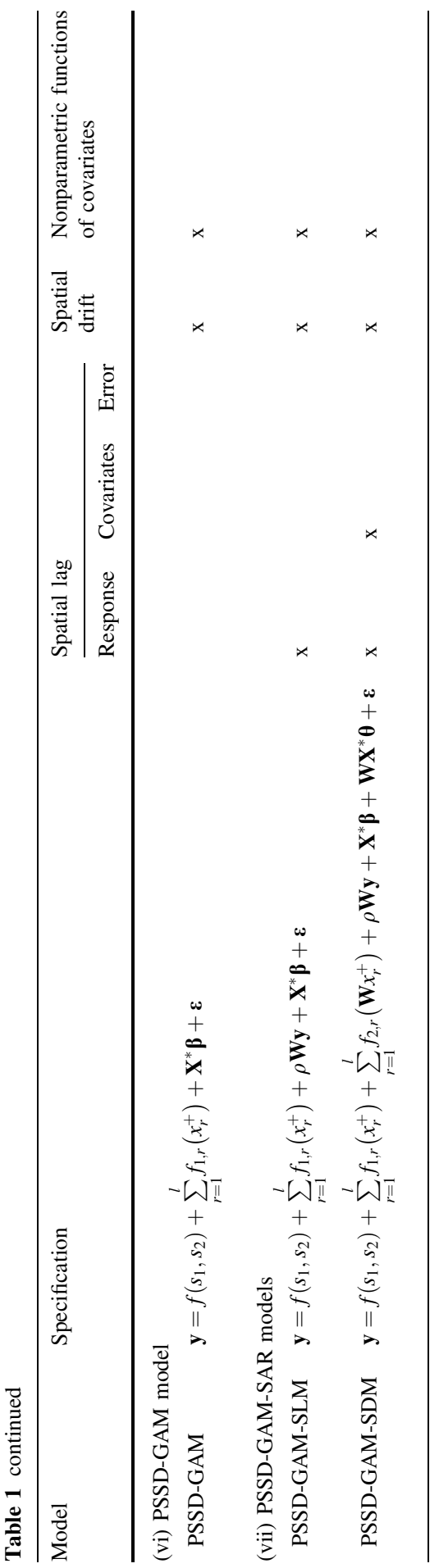

